\title{
Research on Individual Difference Teaching of Advanced Mathematics in Higher Vocational College
}

\author{
Xiaoming Jiang \\ Liaoning Mechatronics College \\ Dandong, China
}

\begin{abstract}
With the continuous extension of the enrollment scales of higher vocational colleges, the quality of new students is uneven and the mathematics level of the students is declining. Advanced mathematics, as an important basic course, plays an important role in the students' follow-up courses and the development of their thinking quality. To meet the needs of different students, we proposed to carry out individual difference teaching to improve teaching quality by teaching students in accordance of their aptitude. We elaborated the background and purpose of the implementation of advanced mathematics individual difference teaching, formulated the curriculum standards, de termined the teaching content and class assignment, teaching methods and assessment plans, and the implementation of individual differences in the specific implementation of the program and the results achieved.
\end{abstract}

Keywords-advanced mathematics, individual difference teaching, curriculum standards, Teaching methods, Assessment program

\section{INTRODUCTION}

With the continuous extension of the enrollment scales of higher vocational colleges, there has been an integrated development of higher education. Although mass education can make higher education more popularized, there are also many negative effects. The qualities of new students are uneven and the levels of the students are declining. There have been some problems because of original class teaching system of advanced mathematics course. For example, students with difficulties in mathematics cannot keep up with the progress of the course so that led to the increase of teaching difficulty and the decrease of the teaching quality. It is a reality that the mathematics levels of the students are uneven. The demands of mathematics level vary from major to major. We proposed individual difference teaching of advanced mathematics according to course characteristics and student situations to meet the needs of different students and make every student get a satisfactory development.

\section{THE BACKGROUND AND MEANING OF INDIVIDUAL DIFFERENCE TEACHING IN ADVANCED MATHEMATICS}

The expansion of higher vocational colleges over the past few years has directly led to higher differentiation of students' advanced mathematics. It is hard for original advanced mathematics teaching model to satisfy the teaching of popular

Comprehensive Education Reform Project of Liaoning Mechatronics College: 'Research and Practice on Implementing a Stratified Teaching Model Reform in Higher Vocational Public Fundamental Courses' education and the teaching quality cannot be guaranteed. Traditional teaching model is unmatched with the needs of society. Students with high mathematics level cannot get enough knowledge in traditional class, while students with low mathematics level cannot keep up with the progress of the course and fail the exams. Students gradually lose interest in learning advanced mathematics.

The main theoretical basis for individual difference teaching is individual differences among students. Individual difference teaching embodies people-oriented, pays attention to level, diversity, effectiveness and pertinence. Only in accordance with their aptitude can we inspire the potential of students. Individual difference teaching can effectively improve students' interest in learning and make students at all levels able to gain something in class. They can experience the joy of learning. We can achieve the teaching effect of teaching students in accordance with their aptitude. At the same time, it effectively compensates for the inadequacies of traditional teaching models.

Individual difference teaching can achieve the effect that the traditional teaching model cannot achieve. In traditional class, students have no interest in learning. It is common that students sleep in class and fail the final exam. In response to this phenomenon, there have been many higher vocational colleges in the province and abroad to carry out the individual difference teaching in advanced mathematics courses.

\section{DEVELOPING ADVANCED MATHEMATICS INDIVIDUAL DIFFERENCE TEACHING}

In Liaoning Mechatronics College, four specialties from Department of Mechanical Engineering including Machinery Manufacturing and Automation, Numerical Control Technology, Precision Machinery Technology, Inspection Technology of Mechanical Products and four specialties from Department of Materials Engineering including Mold Design and Manufacturing, Material Forming and Control Equipment Application and Maintenance, Welding Technology and Automation need one semester to learn advanced mathematics course. The content is the calculus of one variable, which includes Functions and Limits, Derivatives, Indefinite Integral and Definite Integral. There is a pilot project for the reform of individual difference teaching on advanced mathematics in 
freshmen of the Department of Mechanical Engineering and Department of Materials Engineering.

\section{A. The curriculum standards formulating}

The curriculum standards of class A is that, students can gain basic knowledge of the calculus of one variable, basic theory and commonly used calculation methods systemically.

TABLE I. ALLOCATION OF TEACHING CONTENT PERIOD

\begin{tabular}{|c|c|c|c|c|c|c|}
\hline & \multirow{2}{*}{ Teaching unit } & \multicolumn{3}{|c|}{ Period allocation } & \multirow{2}{*}{ Teaching form } & \multirow{2}{*}{ Note } \\
\hline & & Total & Theory & Exercise and test & & \\
\hline 1 & Concept of function and limit & 8 & 8 & 0 & Theory lecture & \\
\hline 2 & Derivatives and differential & 14 & 10 & 4 & Theory lecture & Unit test \\
\hline 3 & Indefinite integral & 8 & 6 & 2 & Theory lecture & \\
\hline 4 & Definite integral & 8 & 6 & 2 & Theory lecture & Unit test \\
\hline 5 & Review & 2 & 0 & 2 & Lecture and practice & \\
\hline
\end{tabular}

TABLE II. COURSE EVALUATION ST ANDARD OF ADVANCED MATHEMATICS (EXAMINATION CLASS)

\begin{tabular}{|c|c|c|}
\hline \multicolumn{3}{|c|}{ Assessment method: Process \& Result } \\
\hline \multicolumn{3}{|c|}{ Process assessment (40points, $40 \%$ of the total score) } \\
\hline Evaluation project & Evaluation standard & Score \\
\hline Usual test & According to the usualmultiple test results & 20 \\
\hline Homework and experience & According to the count and quality of homework & 10 \\
\hline Performance (including attendance) & $\begin{array}{l}\text { According to the performance (including study attitude and discussion, etc.) and } \\
\text { attendance }\end{array}$ & 10 \\
\hline \multicolumn{3}{|c|}{ Result assessment (60points, $60 \%$ of the total score) } \\
\hline Evaluation project & Evaluation standard & Score \\
\hline Final exam & Closed-book exam & 60 \\
\hline \multicolumn{3}{|c|}{ Total evaluation $=$ score of process + score of result } \\
\hline
\end{tabular}

They can also gain essential mathematical basic knowledge and methods for learning follow-up courses and solve practical problems. We want to achieve the purpose of the transfer of knowledge and the ability to develop by teaching. The development of ability need to be carried out during the entire teaching process. The requirements of this course are: gradually develop students' ability to use basic mathematics, self-learning skills, the ability to use the knowledge they have learned to analyze and solve problems, the ability to abstract problems, and logical reasoning skills. Heuristic teaching and ability training need to be carried out during the class teaching. The curriculum standards of class A are higher in students' development of analytical reasoning ability compared with former teaching methods. It is still important to cultivate the ability of learning during college. A man's life is a learning life. Live and learn, where the 'learn' means the self-learning ability. Learn to use inferences by analogy, pass through analogy, and practice the good habit of self-learning through repeated practice during the learning process. Students should be able to practice the analytical skills to solve problems during the learning process and develop students' creative spirit and creative ability, which can benefit students lifelong.

The curriculum standards of class B are different from those before, emphasizing the practical mathematics foundation of the students, and guiding the students' interest in mathematics step by step. Many students in class B were enrolled from technical school by admission exams. Their learning habits and learning ability are different compared with high school students. Sukhomlinskii said,' Everyone loves good children and it is true love to love children who are not so good.' Teachers of class B are facing unprecedented challenges. They must pay more patience and love. They should devote more love to students and care for students with a sincere "love". They must consider more for the students and give them their love to students. To narrow the distance with the students' hearts, there need to be more communication with the students' feelings. Let the students trust their teachers. Considering the low mathematics level and ability to accept of the students, we try to be as easy to understand as possible and avoid theoretical abstraction, appropriately increase the practice time of knowledge, and use multimedia micro lessons. This form fully mobilizes students' learning motivation.

\section{B. The allocation of teaching content period}

The headlines of the teaching content of class A and class B are consistent, and the specific requirements for the degree of difficulty in the knowledge points are not the same. The allocation of period is the same and is shown in Table I. The teaching content of class $\mathrm{A}$ and class $\mathrm{B}$ are shown in Appendix1 and Appendix2.

\section{Teaching methods and assessment plan}

During teaching, various methods such as heuristic teaching, question-based teaching and case introduction method were fully utilized. Platforms for students were established using QQ Group or WeChat Group. Multimedia courseware was used to effectively improve teaching efficiency and effectiveness. In this way, we can develop students' mathematics skills throughout the mathematics class.

The regular grades of class A and class B are both 40, including attendance, homework and daily performance. The final closed-book exam was out of 60 points, including 30 points of basic questions, 20 points for the medium difficulty and 10 points for high difficulty which were prepared for students in class A who want to get a high grade. 
TABLE III. AdVANCED MATHEMATICS A Class PERFoRMANCE St ATISTICS OF 2017 MACHINERY AND MATERIALS DEPART MENT

\begin{tabular}{|c|c|c|c|c|c|}
\hline Performance distribution & $\geq 90$ & $89 \sim 80$ & $79 \sim 70$ & $69 \sim 60$ & $<60$ \\
\hline Percent(\%) & 58.6 & 27.2 & 7.1 & 5.9 & 1.2 \\
\hline
\end{tabular}

TABLE IV. AdVANCED MATHEMATICS B ClASS PERFormanCE ST AT IST ICS OF 2017 MACHINERY AND MATERIALS DEPART MENT

\begin{tabular}{|c|c|c|c|c|c|}
\hline Performance distribution & $\geq 90$ & $89 \sim 80$ & $79 \sim 70$ & $69 \sim 60$ & $<60$ \\
\hline Percent(\%) & 20.1 & 17.2 & 27.1 & 27.6 & 8 \\
\hline
\end{tabular}

\section{Implementation of individual difference teaching of advanced mathematics}

\section{1) Teaching class determining}

At the beginning of the new semester, we carried out a survey during the military training to know the students' requirements and thoughts for advanced mathematics. We also calculated the scores of the students' college entrance examinations and the results of the independent admission examination. It was found that students' math scores were unsatisfactory, and the scores mostly distributed from 30 to 70 . According to the mathematics content of high school and mathematics knowledge used in advanced mathematics, we had a test for freshmen and organized them to participate in it, evaluated and sorted the scores. There are totally six natural classes of four majors in Department of Mechanical Engineering, nine natural classes of four majors in Department of Material Engineering. According to the test results and the students' personal wishes, natural classes from every major in Department of Mechanical Engineering and Department of Material Engineering were reunited into one class A and two class Bs. The scores of the test were sorted from high to low. One-third of the students who got a higher score were formed class A and others were formed class B. Advanced mathematics courses in class A and B were taught at the same time. Students can choose class in the first week and the number of class adjustments was controlled within $10 \%$. In view of the fact that our teacher resources were limited, class A and class B in Department of Mechanical Engineering took courses in two-two classes, while class A and class B in Department of Material Engineering were the grand classes of the three natural classes.

2) Students' amateur life enriching and math vision expanding by developing the second class

The period of advanced mathematics for students in Department of Mechanical Engineering and Department of Material Engineering is 40 hours. Spare time was utilized to carry out knowledge lectures on mathematics culture, mathematics history, mathematical modeling, especially the rapid developing artificial intelligence. With these knowledge lectures, students can understand the branch of mathematics, the history of mathematics and the specific application of mathematics in social life which can let students know the application of mathematics in their current life, allowing students to experience the ubiquity of mathematics and inspire students' interest in learning. The second classroom activity is an advantageous supplement to class teaching.

\section{INDIVIDUAL DIFFERENCE TEACHING EFFECTIVENESS OF ADVANCED MATHEMATICS}

Through a round of individualized difference teaching, remarkable results have been achieved. The following is the final grade distribution table for students of Advanced Mathematics A and B in the Department of Mechanical and Materials Sciences.

The number of students in class A is 169 and the actual number of students is 168 . The highest score: 100 points. The lowest score: 43 The average score: 90.2 The excellent rate reaches $58.6 .7 \%$, the good rate is $27.2 \%$, failing 2 persons accounts for $1.2 \%$.

The number of students in class B is 234 and the actual number of students is 234 . The outstanding excellent rate is $20.1 \%$, and the failing rate is $8 \%$. Due to the large number of students with poor mathematics base in this year's mechanical and material departments, there was a great difference from previous years, which gave us an extra degree of difficulty in teaching. Personalized difference teaching uses various methods and means to mobilize its enthusiasm for learning, achieved a more ideal teaching effect, and achieved the intended purpose.

In particular, the students of the two A classes in the Department of Mechanical Engineering and Materials Engineering are more like fish getting to the water. The atmosphere of the class is active, the initiative for learning is strong, and the interaction between the class students and the teacher is good. The students in the A class establish a QQ for advanced mathematics learning through which students can use ask teachers anytime, anywhere. On this platform you can often see that students discuss mathematics learning content at 9 or 10 in the evening. Through communicating and discussing with teachers and classmates, students can find and study problems, to improve their own learning ability in solving problems and bring students a kind of self-confidence and joy.

There are also some disadvantages in the development of this individualized difference teaching. First, the number of mathematics teachers in our college is relatively small. Our class A and B have taken the form of a large class in churches which has brought great challenges to class B. If they are in a single class, the effect will be very good. Secondly, we should divide the natural classes of each major into the $A$ and $B$ classes of the mathematics class, and to compile statistics on the attendance of students in classes A and B according to the results of the bottom-out test. The results of the end-of-period teachings have brought much extra work to the educational administration system and mathematics teachers. 
Teaching is a career that requires creativity. Teaching must have proper creation, not a mere output. The job of the teacher is not only to deliver the information it receives which is done by excellent teachers, but also to teach students how to study, eliminate students' fear of learning advanced mathematics courses, inspire students' interest, provoke students' enthusiasm and win students' attention. Education is about learning. If you do not learn, you can't talk about education. The purpose of education is to guide people to study, which requires teachers to be good at inspiring students to think and using various means to mobilize the students' enthusiasm for learning. Personalized difference teaching is suitable for the actual situation of students. Teaching students in accordance with their aptitude will greatly mobilize their enthusiasm for learning.

\section{CONCLUSION}

The diversification of sources of students in higher vocational colleges has become a trend for more development of higher vocational education. Individual difference teaching is pointed which can meet the needs of different students. Everyone strives to become talented, everyone can become talented, and everyone develops their talents. It embodied people-oriented, paid attention to level, diversity, effectiveness and pertinence and maximized the potential of students. In particular, mathematics knowledge and mathematical modeling ideas and methods were introduced to students in class A with good mathematics foundations through professional cases. We also introduced the professional application of the learned mathematics knowledge, trained students' ability to apply mathematics knowledge to deal with practical problems and improved the quality of advanced mathematics teaching in higher vocational colleges.

The reform and exploration of higher mathematics teaching content and teaching methods have a long way to go. We need our mathematics educators to accumulate experience and propose new ideas and solutions in the teaching process. We should cultivate students' ability of independent learning, attach importance to stimulating the development of students' interest in learning, attach importance to the use of mathematical thinking methods to analyze problems, solve problems, and effectively improve the teaching quality of higher vocational mathematics classes.

\section{REFERENCES}

[1] Xuecai Liu, Wenzhen Tu.Research on Effect of Stratified Teaching Practice for Higher Mathematics in Higher Vocational CollegesTaking Architecture School of Hubei Polytechnic Institute as an Example[J];Journal of Hubei Vocational and Technical College, 2016(3).

[2] Liping Jiao. Practice and Application of Hierarchical Teaching Methods in Higher Mathematics[J]. Contemporary Educational Practice and Teaching Research, 2016(6).

[3] Shasha Liu. Research on Higher Mathematics Level Teaching in Independent Colleges[J]. Asia Pacific Education, 2016(4).

[4] Hongjun Xiang, Jinhua Wang. Research and Practice of Multi-level Teaching in Basic Mathematics Lessons[J];Journal of Xiangnan University, 2011(2).

[5] Qingli Luo. Practice and Thinking of Higher Mathematics Level-up Teaching in Higher Vocational Colleges[J]. Career. 2017(8):105-106.

[6] Yan Zhao, Yuyu Zhang. Implementation Strategy of Stratified Teaching of Higher Mathematics in Vocational Colleges[J]. Journal of Xiangnan University,2016,37(05):71-73+77.

[7] Shixin Zhou. Analysis on "Leveled Teaching Mode" of Higher Mathematics in Higher Vocational Colleges[J]. Journal of Hulunbeier College,2011,19(01):92-93+100.

[8] Bo Zhang. Higher Mathematics Teaching in Higher Vocational Level [J]. New West (Theory), 2016(11):157-158.

[9] Xiaoxue Nan, Shujun Luo. Exploration and Implementation of Hierarchical Teaching of Higher Mathematics in Higher Vocational Colleges - Taking the Implementation of Multi-level Teaching of Safety Specialty in Chongqing Engineering Polytechnic as an Example [J]. Education and Teaching Forum,2014(51):149-150.

[10] Bo Zhang. Study on the Problems in Higher Mathematics Teaching in Higher Vocational Colleges [J]. Knowledge economy, 2016(15):156157. 
Appendix1

\section{Class A course content}

\begin{tabular}{|c|c|c|c|c|c|}
\hline Index & Teaching unit & Teaching goal & Learning content & Time & Teaching methods and resources \\
\hline 1 & $\begin{array}{l}\text { Function and limit } \\
\text { concept }\end{array}$ & $\begin{array}{l}\text { 1.Understanding function related } \\
\text { concepts } \\
\text { 2.Understand the concept of limits }\end{array}$ & $\begin{array}{l}\text { 1.Function concept, definition domain, value domain, piecewise } \\
\text { function, composite function concept and decomposition } \\
\text { 2.Underst anding numbers and function limits through graphics } \\
\text { Focus: decomposition of complex functions } \\
\text { Difficulties: Underst anding the Limit Concept }\end{array}$ & 8 & $\begin{array}{l}\text { 1.T eaching method } \\
\text { 2.T ask-driven method } \\
\text { 3.Autonomous learning } \\
\text { This unit of knowledge focuses on } \\
\text { understanding. }\end{array}$ \\
\hline 2 & $\begin{array}{l}\text { Derivative and } \\
\text { differentiation }\end{array}$ & $\begin{array}{l}\text { 1. Understand the concepts of } \\
\text { derivatives and differentiation } \\
\text { 2.Skilled in derivative operations } \\
\text { 3. Use derivative to solve practical } \\
\text { problems }\end{array}$ & $\begin{array}{l}\text { 1.Underst anding the concept of derivatives } \\
\text { 2.Basic derivative formula master } \\
\text { 3.Derivatives of various functions } \\
\text { 4.Actual application of derivatives, extremes and peaks. } \\
\text { Focus: Proficient derivative calculation } \\
\text { Difficulties: Understanding Derivatives and Differentials }\end{array}$ & 14 & $\begin{array}{l}\text { 1.Teaching method } \\
\text { 2.Task-driven method } \\
\text { 3.Autonomous learning } \\
\text { This unit is fluent in knowledge. }\end{array}$ \\
\hline 3 & Indefinite integral & $\begin{array}{l}\text { 1.Understand the concept of indefinite } \\
\text { integration. } \\
\text { 2.Proficiency in calculating indefinite } \\
\text { integrals. }\end{array}$ & $\begin{array}{l}\text { 1.Understand the concept, nature of indefinite integration. } \\
\text { 2.Proficient in the direct integration of indefinite points, the first type } \\
\text { of int egration, and the integration of divisions. } \\
\text { Focus: Proficient calculation of indefinite int egrals } \\
\text { Difficulties: Choose theright integration method }\end{array}$ & 8 & $\begin{array}{l}\text { 1.Teaching method } \\
\text { 2.T ask-driven method } \\
\text { 3.Aut onomous learning } \\
\text { This module focuses on the } \\
\text { development of computing skills }\end{array}$ \\
\hline 4 & Definite int egral & $\begin{array}{l}\text { 1.Understand the concept of definite } \\
\text { integral } \\
\text { 2.Mastering Definite Integral } \\
\text { Operators and Applications }\end{array}$ & $\begin{array}{l}\text { 1. Understand the concept of definite integral, the relationship } \\
\text { bet ween indefinite integral and definite integral. } \\
\text { 2. Mastering the definite integral calculation method } \\
\text { 3. Definite integral application in area and volume } \\
\text { Focus: Definite integral calculation } \\
\text { Difficulties: Definite integral application }\end{array}$ & 8 & $\begin{array}{l}\text { 1.T eaching method } \\
\text { 2.T ask-driven method } \\
\text { 3.Aut onomous learning } \\
\text { This unit of knowledge focuses on } \\
\text { application. }\end{array}$ \\
\hline 5 & Review & $\begin{array}{l}\text { Review the key knowledge learned } \\
\text { this semester }\end{array}$ & & 2 & Teach and practice \\
\hline
\end{tabular}

\section{Appendix 2}

\section{Class B course content}

\begin{tabular}{|c|c|c|c|c|c|}
\hline Index & Teaching unit & Teaching goal & Learning content & time & Teaching methods and resources \\
\hline 1 & $\begin{array}{l}\text { Function and limit } \\
\text { concept }\end{array}$ & $\begin{array}{l}\text { 1.Learn about function related concepts } \\
\text { 2.Understanding the limit concept }\end{array}$ & $\begin{array}{l}\text { 1.Function concept, drawing power functions and trigonometric } \\
\text { functions, grasping the concept of composite functions and } \\
\text { decomposition methods } \\
\text { 2.Understanding the sequence of numbers and function limits through } \\
\text { graphs will require several types of function limits. } \\
\text { Focus: decomposition of complex functions } \\
\text { Difficulties: Understanding the Limit Concept }\end{array}$ & 8 & $\begin{array}{l}\text { 1.Teaching method } \\
\text { 2.T ask-driven method } \\
\text { 3.Aut onomous learning } \\
\text { This unit of knowledge focuses } \\
\text { on understanding. }\end{array}$ \\
\hline 2 & $\begin{array}{l}\text { Derivative and } \\
\text { differentiation }\end{array}$ & $\begin{array}{l}\text { 1.Understand the concepts of derivatives } \\
\text { and differentiation } \\
\text { 2.Memorize } 6 \text { commonly used derivative } \\
\text { formulas for simple derivative operations } \\
\text { 3.Use derivative to solve practical } \\
\text { problems }\end{array}$ & $\begin{array}{l}\text { 1. Understand the concept of derivatives. } \\
\text { 2. Memorize } 6 \text { commonly used derivative formulas. } \\
\text { 3. Master the four calculations of the derivative and simply find the } \\
\text { derivative method that matches the function. } \\
\text { 4. The actual application of the derivative, monotonicity, extreme value } \\
\text { and the most value. } \\
\text { Focus: Find the derivative of the function. } \\
\text { Difficulties: Understand the derivative and differential significance. }\end{array}$ & 14 & $\begin{array}{l}\text { 1.Teaching method } \\
\text { 2.Task-driven method } \\
\text { 3.Autonomous learning } \\
\text { This unit is fluent in knowledge. }\end{array}$ \\
\hline 3 & Indefinite integral & $\begin{array}{l}\text { 1.underst and the concept of indefinite } \\
\text { integration. } \\
\text { 2.master the indefinite integral calculation } \\
\text { method. }\end{array}$ & $\begin{array}{l}\text { 1. Understand the concept of indefinite integration. } \\
\text { 2. Master the formulas of } 6 \text { commonly used indefinite integrals, master } \\
\text { the simple direct integration method and the first type of substitution } \\
\text { integral method. } \\
\text { Focus: Calculation of indefinite int egrals. } \\
\text { Difficulties: Choose theright integration method. }\end{array}$ & 8 & $\begin{array}{l}\text { 1.Teaching method } \\
\text { 2.T ask-driven method } \\
\text { 3.Aut onomous learning } \\
\text { This module focuses on the } \\
\text { development of computing skills }\end{array}$ \\
\hline 4 & Definite int egral & $\begin{array}{l}\text { Underst and the concept of definite integral } \\
\text { Mastering Definite Integral Operators and } \\
\text { Applications }\end{array}$ & $\begin{array}{l}\text { 1. Understand the concept of definite integral, the relationship between } \\
\text { indefinite int egral and definite int egral. } \\
\text { 2. Master the method of definite integral calculation. } \\
\text { 3. Underst anding the application of the definite integral in the area } \\
\text { Focus: Definite integral calculation } \\
\text { Difficulties: Definite integral application }\end{array}$ & 8 & $\begin{array}{l}\text { 1.Teaching method } \\
\text { 2.T ask-driven method } \\
\text { 3.Aut onomous learning } \\
\text { This unit of knowledge focuses } \\
\text { on applicat ion. }\end{array}$ \\
\hline 5 & Review & $\begin{array}{l}\text { Review the key knowledge learned this } \\
\text { semester }\end{array}$ & & 2 & Teach and practice \\
\hline
\end{tabular}

